\title{
VULNERABILIDADE E ENVELHECIMENTO: Um estudo das Instituições de Longa Permanência para Idosos em Sergipe
}

\author{
Karyna Batista Sposato \\ Douglas Farias de Morais² \\ Renata Carvalho Martins Lage
}

\section{Palavras-Chave \\ Direito do idoso / ILPI / Vulnerabilidade do idoso / Envelhecimento}

\section{SUMÁRIO}

\section{Introdução. 2. Considerações Metodo-} lógicas e Vulnerabilidade do idoso. 3. Envelhecimento, Definição e Características Sociais das ILPIs. 4. O Direito do Idoso no Brasil. 5. As Instituições de Longa Permanência em Sergipe. 6. Considerações Finais. 7. Referências.

' Doutora em Direito pela Universidade Federal da Bahia (UFBA). Mestre em Direito pela Universidade de São Paulo (USP), onde também se graduou. Atualmente é Coordenadora dos Observatórios Sociais da Universidade Federal de Sergipe, onde tambéma qual está vinculada como Professora Adjunta ano Curso de Graduação em Direito Prprofessora Ppermanente no Programa de Pós-Graduação em Direito (PRODIR). É regente das disciplinas Direito da Criança e do Adolescente e do Idoso, Direito de Família, e Direitos Humanos de Vuilneráveis em perspectiva. E líder do Grupo de Pesquisa Desigualdade (s) e Direitos Fundamentais. Autora das obras "O Direito Penal Juvenil", 2006 , Editora Revista dos Tribunais, e "Direito Penal de Adolescentes -Elementos para uma Teoria Garantista", 2013, Editora Saraiva.

Graduando em Direito pela Universidade Federal de Sergipe- UFS Graduado no Curso de Formação de Oficiais de Bombeiros do CBMDF/UNB em 2003. Graduado em Licenciatura Plena em Matemática pela UFS em 2006

Mestranda em Direito pelo Programa de Pós-Graduação em Direito (PRODIR) da Universidade Federal de Sergipe. Especialista em Desenvolvimento Infantil pela UFMG. Pós-graduanda pela ESA/MG e Graduada em Direito pela IBMEC/MG e graduada em Terapia Ocupacional pela Faculdade Ciências Médicas de Minas Gerais.

\section{Resumo}

O artigo sintetiza os resultados de uma pesquisa empírica sobre as Instituições de Longa Permanência para Idosos (ILPI) em Sergipe, realizada nos anos de 2017 e 2018, e teve como ponto de partida os direitos reconhecidos pela Política Nacional do Idoso, pelo Estatuto do Idoso e pela Constituição Federal de 1988, em contraste com as dificuldades de implementação e efetivação de tais garantias. A pesquisa utilizou-se de dados secundários, a partir de estudo já realizado pelo Instituto de Pesquisa Econômica Aplicada (IPEA) em 2008, sobre as características das instituições de longa permanência para idosos na região Nordeste, e através de estudo empírico realizado in locu nas instituições de longa permanência no estado, foi possível estabelecer uma análise comparativa dez anos depois. Observou-se um aumento do total de idosos residentes em ILPIs em relação ao ano de 2008 , mas esse aumento não representou uma ampliação percentual do número de idosos atendidos, pois não acompanhou o crescimento da população idosa no estado. De outra parte, ao tratar das limitações legislativas, o artigo destaca dispositivos que, na tentativa de proteger o idoso, acabam por limitar sua autonomia, sobretudo dadas as características sociais das ILPIs, que tendem a provocar um afastamento do idoso de outros convívios sociais. Os resultados indicam ainda grandes dificuldades financeiras das instituições para a manutenção dos serviços e a transferência de responsabilidades do poder executivo para instituições filantrópicas em relação à criação e manutenção das ILPIs no estado. Demonstra-se que a fragilidade das políticas públicas e a invisibilização do problema agravam a vulnerabilidade dos idosos. 


\title{
VULNERABILITY AND AGING: A study of the Long-Term Care Institutions for Elderly in Sergipe
}

\author{
Karyna Batista Sposato \\ Douglas Farias de Morais \\ Renata Carvalho Martins Lage
}

Keywords: Elderly Law / LTCI / Elderly

Vulnerability / Aging.

\section{Abstract}

This article synthetizes the results of an empirical research concerning Long-Term Care (LTC) Institutions for elderly people in the State of Sergipe, between the years of 2017 and 2018, and it was part of the activities of the Research Group about Inequalities and Fundamental Rights, and it had its beginning with the elderly rights recognized in the National Policy of the Elderly, the Statute of the Elderly and the Federal Constitution of Brazil from 1988, in contrast with the difficulties of implementation and effectiveness faced by these guarantees. The research used secondary data from a study already conducted by IPEA in 2008 , on the characteristics of long-term care institutions for the elderly in the northeast region of Brazil, and ten years later it was possible to stablish a comparative analysis with an empirical study in these institutions in

Sergipe. There was an increase in the total number of elderly residents in long term care institutions compared to 2008, but this increase did not represent a percentage increase in the number of elderly assisted, as it did not accompany the growth of the elderly population in the state. Concerning legislations limitations, this article emphasizes regulations that instead of protecting the elderly ends up bringing limitation to its autonomy and independence, mainly in social activities, because these institutions tend to put the elderly away from them. The results indicate the financial difficulties of institutions to maintain services and a transfer of the executive's responsibility to philanthropic institutions in relation to the creation and maintenance of LTC Institution in Sergipe, demonstrating that the fragility of public policies aggravates the vulnerability of the elderly.
\end{abstract}




\section{INTRODUÇÃO}

O artigo sintetiza dados e resultados obtidos em pesquisa empírica realizada nos anos de 2017 e 2018 sobre as Instituições de Longa Permanência para Idosos (ILPI) em Sergipe4. Ao observar as principais críticas doutrinárias sobre o sistema jurídico de proteção ao idoso no Brasil, o texto aponta questões que podem contribuir para a perda de autonomia do indivíduo, demonstrando-se também, através dos dados coletados, as grandes dificuldades de implementação e efetivação dos direitos fundamentais do idoso.

A pesquisa oferece um olhar sobre a legislação especial do idoso, com destaque para os textos que regulam as atividades das ILPIS e os instrumentos que tendem a limitar a autonomia do idoso submetido ao contexto asilar. A observação das principais vulnerabilidades que envolvem o contexto das relações sociais entre o idoso e a família, e as interferências do poder público ao ditar os regramentos legais, servem de diretriz metodológica para a análise da condição de sujeitos de direitos dos idosos.

Assim, tornou-se necessário apresentar algumas questões afetas à condição de idoso e do envelhecimento e, em paralelo, as características das instituições de longa permanência, na medida em que tendem naturalmente a contribuir com a perda de autonomia do indivíduo idoso.

Os dados revelam também a omissão do poder público na criação e manutenção destas instituições. Ao estabelecer, em nível

\footnotetext{
${ }^{4}$ Morais, D. F. (2018). Um Olhar Sobre os Direitos Fundamentais e as Instituições de Longa Permanência para Idosos (ILPI) em Sergipe. Trabalho de Conclusão de Curso como requisito para a Graduação em Direito da Universidade Federal de Sergipe, em 2018, integrante do Grupo de Pesquisa Desigualdade (s) e Direitos Fundamentais cadastrado no CNPq. A pesquisa comparou os dados do IPEA de 2008 em relação aos dados obtidos na pesquisa de campo realizada no período de setembro de 2017 a junho de 2018, utilizando-se principalmente de dados do Conselho Estadual do Idoso, dos relatórios do Ministério Público de Sergipe e de questionários aplicados aos gestores das ILPIs de Sergipe.
}

de legislação (Estatuto do Idoso) e de Decreto (1.948/1996), o asilo como última opção de acolhimento, afirma-se que o Estado reconhece o idoso institucionalizado como um dos grupos de maior vulnerabilidade.

A Síntese de Indicadores Sociais (SIS) de 2016, publicada pelo Instituto Brasileiro de Geografia e Estatística (IBGE), aponta a tendência de um crescimento muito mais acelerado da população idosa no Brasil se comparada com os países desenvolvidos. Estes países tiveram mais recursos e mais tempo para o aperfeiçoamento dos sistemas de proteção ao idoso, o que torna a situação brasileira ainda mais preocupante.

\section{CONSIDERAÇÕES METODOLÓGICAS E VULNERABILIDADE DO IDOSO}

A pesquisa buscou observar as características das Instituições de Longa Permanência em Sergipe e condição dos idosos nelas inseridos. Para análise, adotou-se o conceito de ILPI utilizado pelo Conselho Estadual dos Direitos da Pessoa Idosa e pelo Ministério Público Estadual, e o mesmo no tocante às definições de modalidade de atendimento.

Adotou-se como referência o estudo do Instituto de Pesquisa Econômica Aplicada (IPEA, 2008) que identificou 15 ILPIs em Sergipe, às quais se somaram 03 criadas posteriormente, atingindo-se o conjunto de todas as ILPIs reconhecidas pelo Ministério Público do estado e pelo Conselho Estadual do Idoso em Sergipe no universo da pesquisa.

A pesquisa quantitativa utilizou-se de dados secundários a partir do estudo já realizado pelo IPEA, aos quais se acrescentaram dados primários produzidos pelo estudo empírico realizado in locu nas instituições de longa permanência visitadas. A inexistência de um sistema informatizado conten- 
do dados de tais equipamentos somada às dificuldades de acesso aos dados da maior parte das ILPIs em Sergipe exigiu uma pesquisa de campo, realizada através de visitas a todas as ILPIs que são acompanhadas pelo Conselho Estadual do Direto do Idoso e pelo Ministério Público Estadual. Boa parte destas Instituições não possui sítio eletrônico e, em muitos casos, não disponibilizam ou não possuem telefones fixos para contato.

As visitas também proporcionaram ao estudo um viés qualitativo, uma vez que se procurou apurar, através da perspectiva dos gestores, as principais dificuldades enfrentadas no atendimento da população idosa.

Como referido, o primeiro mapeamento das ILPIs no Brasil foi realizado pelo Instituto de Pesquisa Econômica Aplicada em 2008. Os dados relativos ao estado de Sergipe apontaram a existência de 15 ILPIs, localizadas em 13 municípios e com 419 residentes no total, sendo que apenas 378 desses residentes possuíam mais de 60 anos. Esses representavam $0.3 \%$ da população total de idosos em Sergipe.

Os dados coletados na pesquisa de campo, através das visitas às instituições, partiram de questionário estruturado com questões objetivas aos gestores, com o intuito de quantificar: a) a principal fonte de recursos de manutenção das instituições (Governo Federal, Governo Estadual, Município, Doações, Recursos Privados); b) o percentual de idosos que recebiam mais de 02 visitas por mês dos familiares; c) o número de idosos institucionalizados sem nenhuma fonte de renda; d) número de idosos recebendo a prestação judicial de alimentos e ações judiciais promovidas pela Defensoria Pública ou pelo Ministério público em favor dos idosos; e) dificuldades enfrentadas pelos ges- tores de uma ILPI (recursos financeiros, os cuidados com os idosos, a ausência afetiva de familiares ou o licenciamento junto aos órgãos de fiscalização); e f) a natureza jurídica das instituições.

Quanto a esta variável, natureza jurídica das ILPIs, "a maior parte das instituições encontradas em Sergipe é filantrópica (85,7\%), sendo que $64,3 \%$ são filantrópicas religiosas e $21,4 \%$, leigas. Apenas 14,3\% das instituições são públicas." (IPEA, 2008, p. 178).

Sendo possível comparar alguns dos dados após dez anos e diante dos desafios de análise das características das ILPIs, a utilização da pesquisa empírica de campo mostrou-se como a mais adequada, pois o empirismo como metodologia de investigação social tem ganhado destaque nas pesquisas em Direito. Luciana Yeung (2017) ressalta o empirismo como sendo "a prática filosófico-científica de se chegar a conclusões investigativas por meio da observação de dados obtidos pela observação da realidade" (Yeung, 2017, p. 249), apontando a relevância dos trabalhos de Nicolaus I Bernoulli em 1709 e do estatístico Francês Simeon Denis Poisson de 1837 na área do Direito. Este último, famoso por demonstrar a distribuição estatística de Poisson, livro em que trata da probabilidade de julgamentos em matéria criminal.

Outra referência relevante para a análise apresentada aproveita a ideia da interseccionalidade, conceito cunhado por Kimberle Crenshaw (2002). A autora estabelece o conceito da interseccionalidade na discriminação de raça e gênero em contraponto às visões tradicionais que, ao abordar aspectos específicos de um ou de outro grupo, acabam por limitar a real dimensão do problema que muitas vezes não se restringe a de- 
terminado grupo ou condição.

A autora sugere a possibilidade de ocorrências de sobreposições de vulnerabilidades em que o mesmo indivíduo sofre discriminação racial, discriminação de gênero, discriminação de classe, discriminação em razão de deficiência ou da idade, possibilitando uma análise multidimensional que não se restrinja a apenas um enfoque de proteção.

A condição de vulnerabilidade dos idosos nas ILPIs em Sergipe tende a reunir condições de vulnerabilidade multidimensional: individual, familiar e sociojurídica. Do ponto de vista individual caracterizada pela ausência ou insuficiência de recursos individuais para a realização das atividades básicas e pelos altos índices de problemas de saúde que acometem os idosos. A vulnerabilidade familiar é caracterizada seja pela ausência do convívio e dos cuidados dos parentes, seja pela baixa frequência de visitas de familiares, e a vulnerabilidade sociojurídica se caracteriza pela inexistência, insuficiência ou deficiências estruturais de instituições criadas e mantidas pelo poder público, pelo baixo valor das aposentadorias e pensões definidas legalmente, e pela ineficiência da garantia de direitos dos idosos nas instituições que residem.

Dessa forma, aspectos relacionados ao processo de envelhecimento e a descrição das características sociais das ILPIs evidenciam as vulnerabilidades apontadas. Paralelamente à análise dos dados das ILPIs, a discussão em torno da proteção social e jurídica dos idosos e das limitações ainda existentes reforçam a preocupação em torno das vulnerabilidades apontadas.

\section{ENVELHECIMENTO, DEFINIÇÃO E CARACTERÍSTICAS SOCIAIS DAS ILPIS}

As causas do envelhecimento ainda intrigam cientistas do mundo todo. Em resumo sobre o tema, Guiomar Silva Lopes (2011) traz as hipóteses chamadas estocásticas, baseadas no acúmulo de erros no DNA que provocaria mudanças estruturais no indivíduo que envelhece, e relembra os estudos sobre a estrutura terminal do cromossomo, que funcionaria como relógio biológico, conceito que rendeu o prêmio Nobel de Medicina de 2009 aos autores Elizabeth Blackburn, Carol Greider e Jack Szostack.

A distinção entre velhice e doença é um tema bastante controvertido entre os pesquisadores, a diferenciação entre senescência e a senilidade tende a mudar a concepção sobre o idoso. Beauvoir (1970) aponta distinções entre a velhice e a doença, entendendo que a doença se apresenta com maior evidência para o paciente do que para aqueles que o cercam. Enquanto que "a velhice aparece com maior clareza aos olhos dos outros que aos do próprio sujeito" (Beauvoir, 1970, p. 8).

Descrevendo a história da senescência e da senilidade, Farfel (2008) faz menção ao estudo dos historiadores que apontam para a descrição em 1907 do primeiro caso de Alzheimer, pesquisador que emprestou o nome a doença. $O$ autor cita a classificação etária de Pitágoras no século VII A.C, (7, 21, 49, 63 e 81 anos), chamando as duas últimas de senium. Já Hipócrates, no século IV A.C, considerava as alterações cognitivas inerentes ao envelhecimento. Na mesma linha, Aristóteles considerava o envelhecimento e o declínio mental inseparáveis.

Farfel (2008) destaca a percepção diferenciada de outros autores da época, em especial a visão de Cícero, jurista e filósofo do século II A.C, autor do livro "Saber Envelhe- 
cer", que teria sido o primeiro a distinguir o envelhecimento natural do envelhecimento patológico. Na contramão do que se acredita hoje, ainda no Século II, o médico romano Galeno considerou o envelhecimento como uma infecção inevitável do corpo, ideia que só fora rebatida no século XIX, quando o médico francês Philippe Pinel conseguiu convencer a sociedade, que mantinha os idosos debilitados em prisões, de que a deterioração cognitiva não deveria ser encarada como crime e sim como doença. Cícero (2001), no livro "Saber Envelhecer" do século II A.C, sugeria a prática de exercícios que retardariam a perda cognitiva, destacava a participação política de idosos em importantes sociedades e apresentava as vantagens trazidas pelos anos vividos. Em relação ao conceito ou definição de envelhecimento, outras ciências, além da medicina, têm trazido grandes contribuições. Debert (1999), baseada em estudos de antropologia, relata a ausência do parâmetro de idade cronológica como definição de envelhecimento na maioria das sociedades orientais. Segundo a autora, a definição legal que elege o critério cronológico para a determinação da velhice cria: "um mecanismo básico de atribuição de status (maioridade legal), de definição de papéis ocupacionais (entrada no mercado de trabalho), de formulação de demandas sociais (direito à aposentadoria)" (Debert, 1999, p. 46).

O modelo simples de definição da velhice facilita a solução em caso de lide judicial, no entanto a legislação brasileira acabou criando diferentes parâmetros etários para concessão de direitos: a definição de idosos aos 60 anos, o direito ao Benefício da Prestação Continuada (BPC) aos 65 anos, a idade compulsória diferenciada, as diferentes idades da legislação penal, processual, previdenciária e trabalhista acabam relativizando a vantagem de uniformização do critério etário.

Em relação à definição das ILPIs, não há consenso no Brasil. Camarano e Kanso (2007) afirmam que a Sociedade Brasileira de Geriatria e Gerontologia (SBGG) sugeriu o termo ILPI por entender que tais instituições desempenhavam um papel híbrido de assistência social e assistência à saúde, pelo fato de a legislação não diferenciar com clareza as clínicas de repouso, asilos, clínicas geriátricas, abrigos e, para aproveitar a nomenclatura adotada internacionalmente Long-term care institution. Logo,

As ILPI são estabelecimentos para atendimento institucional integral, de indivíduos dependentes ou independentes que não dispõem de condições para permanecer com a família em seu domicílio. Essas instituições, conhecidas por denominações diversas, (abrigo, asilo, lar, cada de repouso, clínica geriátrica e ancianato), devem proporcionar serviços nas áreas de assistência social, medicina, psicologia, enfermagem, terapia ocupacional, odontologia e fisioterapia, mantendo os idosos saudáveis e independentes para realizar atividades da vida diária (AVD), evitando a instalação e o agravamento de doenças advindas da inatividade e a falta de orientação do idoso e seus familiares (SBGG, 2003).

Após a adoção do termo ILPI pela SBGG, o estado brasileiro passou a adotar o conceito estabelecido na RDC 283, de 26 de setembro de 2005:

Instituições de Longa Permanência para Idosos (ILPI) são instituições governamentais ou não governamentais, de caráter residencial, destinada a domicilio coletivo de pessoas com idade igual ou 
superior a 60 anos, com ou sem suporte familiar, em condição de liberdade e dignidade e cidadania. (Agência Nacional de Vigilância Sanitária [ANVISA], 2005, p.3). Grifo nosso.

É importante destacar que o conceito não se refere à modalidade de atendimento asilar, definido através do artigo $3^{\circ}$ do decreto 1948/96 que regulamenta a Lei Federal 8.842 (Política Nacional do Idoso), como foi dito anteriormente. $O$ conceito trata da definição da Instituição e não da modalidade de atendimento.

Assim, por esta definição da RDC 283, a ILPI deve acolher idosos, que passarão a tê-la como domicílio coletivo, independente do suporte familiar, mantendo-se a condição de liberdade, dignidade e cidadania. Nesta abordagem, as críticas de priorização do critério patrimonial e da exigência de inexistência de amparo familiar em detrimento da capacidade jurídica do idoso estariam minimizadas.

A fragilidade das definições referentes às modalidades de atendimento e dos tipos de instituições, associada à deficiência no número e na estrutura das instituições especializadas no tratamento dos idosos, tem trazido uma série de problemas práticos relacionados à permanência de idosos em determinadas instituições. Por diversas vezes, instituições públicas que prestam serviços na modalidade Casa-Lar, que teoricamente seriam obrigadas a prestar atendimento temporário aos acolhidos, deparam-se com idosos que não possuem amparo familiar e recursos suficientes para se desligarem da instituição, permanecendo por mais tempo.

Nestes casos, a remoção do indivíduo para uma ILPI tende a enfrentar todos os problemas de quebra das relações afetivas e do sentimento de pertencimento do idoso àquela primeira instituição. As relações sociais desenvolvidas em instituições deste tipo (ILPI e Casa-Lar com longos períodos de atendimento) apresentam peculiaridades que merecem uma observação especial, sendo pertinente relembrar o conceito de instituição total de Goffman (1992):

Uma instituição total pode ser definida como um local de residência e trabalho onde um grande número de indivíduos com situação semelhante, separados da sociedade mais ampla por considerável período de tempo, levam uma vida fechada e formalmente administrada (Goffman, 1992, p. 11).

De acordo com o autor, as instituições totais tendem a quebrar uma disposição básica da vida comum onde o indivíduo tende a dormir, brincar e trabalhar em diferentes lugares, sob autoridades diferentes, e acrescenta que: "o aspecto central das instituições totais pode ser descrito como a ruptura das barreiras que comumente separam essas três esferas da vida" (Goffman, 1992, p. 71).

Dessa forma, a ILPI torna-se o novo, e muitas vezes o único ambiente social do idoso, seu novo lar, seu outro mundo. Nessa nova etapa, o idoso irá enfrentar todas as dificuldades da vida e, de forma inversa ao período da infância, tentará superar as consequências de sua perda de autonomia.

Em relação às características de instituições totais das ILPIs, é suficiente considerar a possibilidade de aceleração da perda de autonomia, seja pelo avançar natural da idade, seja por patologias, ou ainda pela falta de participação política do idoso na gestão das instituições e de outros grupos fora delas.

Silva (2009) apresenta estudos de geriatria, 
propostos por enfermeiros, médicos, fisioterapeutas e outros profissionais que observam a capacidade funcional de idosos institucionalizados, quanto à realização de Atividades da Vida Diária (AVD). Descobrir o equilíbrio entre a necessidade de auxílio e a preservação da autonomia do idoso é um desafio diário para os cuidadores, e tem despertado a atenção de pesquisadores acadêmicos.

A Resolução 283 da Agencia Nacional de Vigilância Sanitária (ANVISA) já apresentou preocupação com a perda de autonomia, apresentando três graus de dependência ${ }^{5}$ relacionados à capacidade de realização das atividades da vida diária pelo idoso.

Associada a estas dificuldades de perda de autonomia, surge a necessidade de os gestores das ILPIs estabelecerem rotinas que garantam um ambiente saudável aos idosos, servindo alimentação e ministrando medicamentos em horários regulares, preservando ambientes limpos e organizados, sem, no entanto, deixar de respeitar a individualidade de cada indivíduo idoso.

O tema das rotinas institucionais é algo que merece particular atenção, a ideia de instrumentalidade da disciplina trazida por Foucault (2007, p. 24) alerta para os riscos da perda da autonomia e identidade do sujeito, pois geram uma forma de controle disciplinar sobre as subjetividades e individualidades. Se, por um lado, a organização dos horários de refeições, o acompanhamento dos horários de ministrar medicamentos e a necessidade de organização da rotina dos idosos é necessária, é também imprescindível garantir o exercício de direitos e de par5 A resolução 283 da ANVISA estabelece três graus de dependência relacionados à capacidade de realização das atividades da vida diária pelo idoso. No grau I, os idosos independentes, ainda que requeiram equipamentos de autoajuda. No grau II, idosos com dependência em até três atividades de autocuidado. E grau III, idosos com comprometimento cognitivo, ou que requeiram assistência em todas as atividades de autocuidado para a vida diária.

ticipação.

Outro aspecto relevante se refere à regulação de horários como fortes instrumentos disciplinares, "o tempo penetra o corpo, e com ele todos os controles minuciosos do poder" (Foucault, 2007, p. 129). Para Foucault, a disciplina se constitui em "métodos que permitem o controle minucioso das operações do corpo, que utilizam a sujeição constante de suas forças, e lhes impõe uma relação de docilidade-utilidade" (Foucault, 2007, p.118). Nos asilos, a perda cognitiva dos idosos pode ser agravada caso não haja atenção especial para a promoção de exercícios que retardem estas perdas e estimulem a autonomia do idoso.

Ao mesmo tempo em que a organização do espaço e das atividades diárias exigem rotinas gerais que interferem diretamente na vida e no horário biológico do idoso, o desrespeito às individualidades tende a agravar os problemas de despersonalização do indivíduo como afirma Goffman (1992). Conciliar tais necessidades de organização e de preservação da autonomia ${ }^{6}$ do idoso passa a ser um grande desafio aos gestores de ILPIs.

Sob outro aspecto, a luta por autonomia do idoso nas ILPIs não pode ser confundida com uma busca exacerbada por um enveIhecimento ativo. Braga (2011) alerta sobre a necessidade de se buscar um caminho intermediário que preserve a autonomia do idoso sem, no entanto, obrigá-lo a ocupar o posto de idoso ativo. Na cultura ocidental, como afirmou-se anteriormente, a imposição de papéis, através da legislação, tende a criar e reforçar determinados comportamentos, e quando estes parâmetros se tor-

${ }^{6}$ A questão de autonomia dos idosos pode ser estudada sobre vários aspectos, a pesquisadora Silva (2009) analisou a capacidade funcional e a aptidão Funcional de idosos em ILPIs em sua dissertação de mestrado. Um critério bastante conhecido se refere a realização das Atividades da Vida Diária (AVD) que estabeleceu graus de autonomia (Resolução 283 da Anvisa). 
nam inatingíveis para alguns indivíduos, é possível que a perda de autonomia por parte do idoso seja ainda mais agravada.

A ONU tem reforçado a necessidade de promoção de um envelhecimento ativo aos idosos e, nesta questão, Silva (2012) articula esta necessidade aos instrumentos normativos internacionais. De acordo com o autor, a compreensão da fragilidade do idoso revela a visão protetiva da legislação internacional, a necessidade de estabelecer medidas de proteção e, por último, traz a preocupação com a questão do status de autonomia do idoso. Para o autor, é necessária a construção de uma imagem positiva "que Ihes assegure autoestima e não discriminação quanto às suas competências e à sua própria imagem como protagonista social" (Silva, 2012, p. 85).

Embora possa haver divergência sobre considerar as ILPIs como instituições totais, parece haver consenso no tocante aos riscos de agravamento da perda de autonomia, ou da capacidade de realização das Atividades da Vida Diária (AVD) pelos idosos institucionalizados. As características sociais das ILPIs, por sua própria natureza, denotam um risco potencial de limitação do convívio do idoso em outros ambientes sociais, capazes de acelerar a perda cognitiva, diminuindo a atuação política do idoso nos diversos ambientes de formulação de políticas de cuidado.

As divergências acadêmicas, legislativas e culturais sobre o conceito de envelhecimento, associadas à pluralidade de critérios normativos para a definição das garantias do idoso reforçam a necessidade de ampliação dos estudos que avaliem os impactos de perda de autonomia nos idosos residentes nas ILPIs e se apontem alternativas de acolhimento para estes idosos que estão inseridos em uma zona de coincidência de uma série de vulnerabilidades, já apontadas neste trabalho.

Sobre a dimensão normativa, pretende-se realizar a seguir uma breve evolução do direito do idoso no Brasil, destacando as possibilidades de ampliação da vulnerabilidade do idoso nas ILPIs de Sergipe, seja por suas características sociais, seja pela deficiente estrutura legal e pública de garantia de direitos, e correlatamente pela própria vulnerabilidade do idoso.

\section{O DIREITO DO IDOSO NO BRASIL}

Uma das primeiras legislações nacionais a tratar da questão do idoso no Brasil se refere à lei dos sexagenários, de 28 de setembro de 1885. A falta de efetividade da lei por não alcançar a maior parte dos escravos que não conseguiam atingir a idade, a necessidade de os escravos precisarem continuar trabaIhando para não morrerem de fome nos engenhos e a libertação dos idosos sem amparo, promovia uma situação de mendicância que agravava a condição de sobrevivência do idoso e exibia um problema social que precisava de solução (Diniz, 2011, pp.18-19).

Alcântara (2004), ao tratar da origem do chamado Direito asilar no Brasil, remete ao período colonial, registrado na preocupação do Conde Resende (V Vice-Rei) em amparar os soldados idosos diante da velhice, enfermidade e pobreza. Ao escrever uma carta à Coroa Portuguesa e conseguir a autorização para o funcionamento da Casa dos Inválidos, no ano de 1794, mantida pelo V Vice- Rei, "baseada não na caridade, mas no direito a um final de vida tranquilo pelos serviços prestados à Pátria" (Alcântara, 2004, p. 33), o Conde traduz a necessidade de preocupação do Estado com os militares que deveria ser estendida a todos os idosos de nosso país. 
A autora descreve o contexto de institucionalização dos idosos em ambientes associados a enfermos, mendigos e outras condições de vulnerabilidade social, destacando a caridade cristã como possibilidade de acesso para se obter assistência. Ao adotar a nomenclatura da filantropia para caracterizar o período da segunda metade do século XIX a meados do século XX, marcados pela queda da Monarquia e separação da Igreja do Estado, ela destaca um redimensionamento da administração da pobreza, onde a filantropia dá continuidade à caridade (AIcântara, 2004).

Nesse período, em Sergipe, é possível destacar a criação do Asilo Santo Antônio, no município de Estância em 1907, e o SAME (Serviço de Assistência e Mendicância), no município de Aracaju em 1949, ambos ligados à Igreja Católica. Essas duas instituições foram identificadas na pesquisa, como as mais antigas do Estado de Sergipe. Ainda voltando o olhar para a origem dos asilos, registra-se no início do século XX que a mudança do tipo de mão de obra escrava para assalariada no sistema de produção teria ampliado a exposição da necessidade de cuidado com os idosos, afastados do modo de produção. A partir de então, surgem as Casas de Pensão e outros sistemas de previdência privada. Cabrera (2006) cita a Constituição de 1934 como a primeira a tratar do direito do idoso, mais especificamente ao instituir a obrigação previdenciária do trabalhador, sendo seguida pelas Constituições de 1937, 1946 e 1967.

Atualmente, a Constituição Federal de 1988 manteve a proteção previdenciária ao idoso em seu inciso I, do Art. 201 e impediu a redução do salário mínimo. A assistência social estabelecida no inciso I, do Art. 203 da CF, afirma que ela será prestada a quem dela necessitar, independente de contribuição à seguridade social, tem por objetivos: a proteção à família, à maternidade, à infância e à veIhice". (inciso I, Art. 203, CF 1988), trazendo no seu inciso V: "a garantia de um salário mínimo de benefício mensal à pessoa portadora de deficiência e ao idoso que comprovem não possuir meios de prover à própria manutenção ou de tê-lo provida por sua família, conforme dispuser a lei (Brasil, 1988).

Em normativa infraconstitucional, a legislação previdenciária que trata dos benefícios da Previdência Social traz os requisitos da aposentadoria por idade, e as leis 8.213 e 9.873 disciplinam a aposentadoria dos funcionários públicos.

Ao tratar da família da criança, do adolescente e do idoso, a Constituição estabelece nos artigos 229 e 230, a obrigação dos filhos de ajudar e amparar os idosos, destacando no caput do artigo 230 a obrigação do Estado, da família e da sociedade no dever de amparar os idosos. Almeida (2017) trata da teoria do abandono afetivo inverso, apoiada na teoria tradicional de abandono afetivo dos pais em relação aos filhos. A autora sustenta que o princípio da afetividade é o sustentáculo das atuais relações familiares e deve reger as relações com os idosos. Tal teoria tem ganhando lugar de destaque em recentes decisões jurisprudenciais.

O dever de prestar alimentos ao idoso tem sido considerado pelos tribunais uma obrigação solidária, por força da previsão estatutária, em contraponto ao Código Civil. Assim, a prestação de alimentos pode ser ajuizada contra qualquer dos membros da família que tenha o dever legal da prestação e apresente melhores condições de colabo- 
rar com as despesas do idoso. Apesar da relevância jurídica do tema, a pesquisa não identificou nenhuma ação judicial em favor de idosos asilados em Sergipe e nenhum deles recebendo a prestação judicial de alimentos.

Em relação ao Direito Previdenciário e ao Benefício da Prestação Continuada (BPC), é possível afirmar, com base nos Dados do IBGE, em especial com base na Síntese de Indicadores Sociais de 2016, que estas previsões representam a principal fonte de renda dos idosos no Brasil e nas ILPIs de Sergipe.

Em crítica à Proposta de Emenda à Constituição (PEC) 278/2016, Giacomo (2017) denuncia a lesão dos direitos fundamentais do idoso e da pessoa com deficiência que hoje estariam amparados pelo BPC e que, em caso de mudança do critério etário para 70 anos e da atual forma de cálculo, seriam prejudicados. O autor destaca que apesar da previsão normativa (Lei Orgânica de Assistência Social) da renda per capita não superior a 1/4 do salário mínimo, os tribunais superiores vinham concedendo o limite de 1/2 salário mínimo como renda per capita máxima para a concessão do benefício. As mudanças trariam um retrocesso ao reconhecimento do direito dos idosos, tanto por parte da legislação quanto por parte da jurisprudência.

A questão patrimonial continua a ser um dos principais problemas dos idosos em ILPIs de Sergipe. Os resultados da pesquisa nas ILPIs de Sergipe atestam que atualmente o BPC e a Aposentadoria representam a principal fonte de manutenção da condição de sobrevivência do idoso das ILPIs, evidenciando a dimensão pública e de assistência associada ao tema.

O Poder Público não tem oferecido instituições para atender a esta demanda e não tem colaborado com instituições filantrópicas que desempenham esta função. A pesquisa apontou que apenas duas instituições em Sergipe são mantidas pelo Poder Público, enquanto as outras não têm recebido apoio financeiro de nenhuma esfera de governo, embora o decreto federal 1.948/1996 estabeleça em seu artigo 17, parágrafo único, que

O idoso que não tenha meios de prover a sua própria subsistência, que não tenha família ou cuja família não tenha condições de prover a sua manutenção, terá assegurada a assistência asilar, pela União, pelos Estados, pelo Distrito Federal e pelos Municípios, na Forma da Lei (Brasil, 1996).

Piorando a condição de manutenção de muitas instituições que sobrevivem com recursos dos idosos institucionalizados, o Estatuto do Idoso

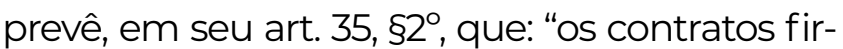
mados entre o idoso e as instituições não podem comprometer mais de 70\% da sua renda" (Brasil, 2003). Um dispositivo que visa proteger, mas pode dificultar os cuidados de idosos em situação de total dependência institucional.

Outra questão conflitante do Estatuto do Idoso, que tem recebido críticas doutrinárias, refere-se à previsão do artigo $3^{\circ}$. Esse dispositivo elege a família, a comunidade a sociedade e, por último, o Poder Público, como responsáveis pelos cuidados dos idosos. O próprio texto da lei estabelece o atendimento asilar como última das possibilidades: "priorização do atendimento do idoso por sua própria família, em detrimento do atendimento asilar, exceto dos que não a possuam ou careçam de condições de manutenção da própria sobrevivência" (Brasil, 2003).

As críticas se referem principalmente ao critério que afasta a capacidade jurídica e a vontade (autonomia) do idoso em optar pelo lugar onde viver, e estabelece a vulnerabilidade social como a causa que conduz o idoso para a última opção de cuidado: o asilo.

Na mesma linha, a lei 8.842 estabelece a Po- 
lítica Nacional do Idoso e apresenta no inciso VIII do artigo 4: "A priorização do atendimento ao idoso em órgãos públicos e privados prestadores de serviços, quando desabrigados e sem família" (Brasil, 1994). A lei estabelece ainda o órgão ministerial de assistência social, os conselhos nacionais, estaduais e municipais do idoso para sua gestão.

O Decreto Federal 1948/96 define a modalidade asilar e não inclui, nesta definição, a possibilidade de regime semiaberto:

Art. $3^{\circ}$ Entende-se por modalidade asilar o atendimento, em regime de internato, ao idoso sem vínculo familiar ou sem condições de prover à própria subsistência de modo a satisfazer as suas necessidades de moradia, alimentação, saúde e convivência social.

Parágrafo único. A assistência na modalidade asilar ocorre no caso da inexistência do grupo familiar, abandono, carência de recursos financeiros próprios ou da própria família (Brasil, 1996).

Mais uma vez, a vontade do idoso e a capacidade jurídica dão lugar à questão patrimonial, reforçando o estigma de vulnerabilidade social aos que são acolhidos nesta modalidade de atendimento.

As modalidades de atendimento não asilar são estabelecidas no artigo $4^{\circ}$ do decreto, destacando-se a previsão do inciso III que caracteriza a Casa-Lar. Essa última modalidade, surge como fuga do estigma da nomenclatura de asilo ou de ILPI, porém acaba por abrigar idosos na condição de atendimento integral, nas mesmas condições descritas no artigo $3^{\circ}$.

Dessa forma, as Casas-Lar, em especial as entidades públicas, enfrentam um novo problema, pois ao tentar afastar o idoso destas instituições, depois de longos períodos de atendimento, precisam buscar alternativas para minimizar os prejuízos psicológicos ao idoso, devido à quebra do sentimento de pertencimento à instituição que as características do internato tendem a construir.

Outro ponto que merece destaque se refere à ausência da exigência legal da participação do idoso na composição dos conselhos, conforme previsão do artigo $6^{\circ}$ da lei federal 8.842. A inclusão de instrumentos legais que busquem a preservação da autonomia representaria uma oportunidade de contraposição a uma série de dispositivos legislativos que, ao buscar proteger, acabam por limitar a autonomia do idoso.

Nesta perspectiva, Silva (2012) destaca a perda de autonomia do idoso, apontando a perda natural de capacidade física, relacionada à senescência, e a perda como consequência de alterações patológicas, que atinge grande número de idosos, tipificando a senilidade. A generalização destas características pode ter contribuído para uma produção legislativa que considera o idoso incapaz, ou que privilegia a questão patrimonial em detrimento da preservação de autonomia do idoso. A aposentadoria compulsória, a limitação de escolha de determinado regime de divisão de bens no casamento, o voto facultativo e uma série de outros dispositivos constitucionais ou infraconstitucionais, ao presumir a incapacidade do idoso, estariam ferindo a preservação de sua autonomia como cidadão.

No caso das ILPIs, as dificuldades de manutenção da capacidade jurídica e da participação cidadã do idoso podem ser agravadas pela aceleração da perda da capacidade funcional dos idosos institucionalizados, como aponta Aline Huber Silva (2009) em sua dissertação de mestrado sobre o tema.

Na mesma linha, Diniz (2011), tratando do re- 
gime de incapacidades do idoso, estabelece críticas às decisões jurídicas que beneficiam a preservação patrimonial em detrimento da proteção da personalidade humana. A autora propõe a metodologia de interpretação constitucional como forma de superar as limitações legislativas que prejudiquem a preservação da autonomia do idoso.

A necessidade de fortalecimento da participação política como forma de concretização de direitos fundamentais deve ser um exercício de cidadania essencial ao ser humano, e não deve ser afastado dos idosos em ILPIs. Aristóteles destacava essa perda de autonomia na sociedade e, para definir o que ele chamava de cidadão puro, descartava as crianças por não possuírem idade para exercerem função cívica e os velhos que estariam isentos de qualquer serviço, "uns são cidadãos em esperança por causa de sua imperfeição, outros são rejeitados por causa de sua decrepitude" (Aristóteles, 2002, p. 31)
A modificação do olhar sobre a legislação de proteção ao idoso poderá trazer reformulações legislativas e jurisprudenciais que contribuam com a luta pela preservação da autonomia do idoso na sociedade e nas ILPIs.

\section{AS INSTITUIÇÕES DE LONGA PERMANÊNCIA EM SERGIPE}

Os dados produzidos pela pesquisa de campo, associados à pesquisa do IPEA, refletem um perfil institucional do atendimento e da política para idosos em Sergipe.

As principais variáveis observadas estão dispostas na tabela abaixo e foram colhidas pelo questionário e completadas em alguns casos por dados fornecidos pelo Ministério Público de Sergipe e pelo Conselho Estadual dos Idosos. Como se observa, apenas um município, Propriá, não respondeu ao questionário, tendo sido supridas algumas das informações.

\begin{tabular}{|l|l|l|l|l|l|}
\hline Municípios & ILPI & Fonte Rec. & Criação & Recebem 2 visitas/mês & Idosos \\
\hline Aquidabã & Casa de Rep. Padre Júlio & Privado & 2000 & Mais de 50\% & 16 \\
\hline Aracaju & Asilo Rio Branco & Privado & 1911 & Mais de 50\% & 25 \\
\hline Aracaju & Casa Nalde Barbosa & Público & 2013 & Menos de 10\% & 7 \\
\hline Aracaju & Lar Dulce Lar & Privado & - & Mais de 50\% & 2 \\
\hline Aracaju & Solar da Vovó & Privado & 2013 & Mais de 50\% & 9 \\
\hline Aracaju & Residencial Meu Aconchego & Privado & 2016 & Mais de 50\% & 15 \\
\hline Aracaju & SAME & Privado & 1949 & Mais de 50\% & 60 \\
\hline Boquim & Lar S. F. de Assis & Privado & 1982 & Mais de 50\% & 13 \\
\hline Estância & Asilo Santo Antônio & Privado & 1907 & Mais de 50\% & 35 \\
\hline Itabaiana & Lar Cidade de Deus & Privado & 2003 & Mais de 50\% & 68 \\
\hline Lagarto & PIA U. dos Pobres S. Antônio & Privado & 1973 & Menos de 10\% & 40 \\
\hline N. S. Da Glória & Lar Sag. Cor. de jesus & Privado & $2017 *$ & Menos de 50\% & 11 \\
\hline Propriá & Rec. do idos. P. Paes & Privado & $\mathrm{n} /$ resp. & N/ resp. & 25 \\
\hline Ribeirópolis & A. de P. Idos. M. do Carmo & Privado & 1987 & Menos de 10\% & 20 \\
\hline Ribeirópolis & Lar Dona Conceição & Privado & 1998 & Mais de 50\% & 40 \\
\hline São Cristóvão & Lar Isaias Gil. Barreto & Privado & 1984 & Entre 10 e 30\% & Menos de 10\% \\
\hline Simão Dias & Lar São Francisco de Assis & Público & 1991 & Mais de 50\% & 18 \\
\hline Tobias Barreto & Abrigo São Vicente & Privado & 1981 & 30 \\
\hline
\end{tabular}

Tabela: 01

*A instituição foi criada em data anterior, porém mudou de sede em 2017.

Dados: Questionário de pesquisa e Dados do Ministério Público. 
Os dados acima indicam o município e a instituição pesquisada, a principal fonte de recursos para a manutenção das ILPIs, o ano de criação, o percentual de idosos que recebem mais de duas visitas por mês e o total de idosos da instituição. O critério de quantificação do idoso foi o adulto com mais de 60 anos de idade.

Seja por orientação do Ministério Público Estadual, seja por regras estabelecidas pelos gestores das ILPIs, muitos dos contratos de cuidados entre a instituição e o idoso prevê visitas regulares dos familiares. Nos casos em que a ILPI abriga idosos sem contatos de familiares, o percentual de visitas tende a diminuir, ampliando a vulnerabilidade familiar do idoso.

O Lar Dona Conceição, localizado no município de Ribeirópolis, é mantido pela fundação Pedro Paes Mendonça, e corresponde a uma das mais bem estruturadas ILPIs do Estado de Sergipe. Os idosos que residem nesta ILPI não contribuem para a manutenção das instalações e nem com as despesas do Lar, e podem utilizar os recursos de aposentadoria, renda ou qualquer outro benefício sem a preocupação de contribuir com a ILPI. A instituição é muito bem gerenciada e representa um bom exemplo de que é possível manter ILPI com qualidade e ofertar estes serviços para que outros idosos possam optar por residir em uma.

Para identificar o percentual de idosos residentes em ILPI, após 10 anos do estudo do IPEA, a pesquisa de campo aproveitou os dados da síntese de indicadores de 2016 e da projeção da população para o ano de 2018 (IBGE, 2018), calculando a população idosa com base na média do percentual de idosos previstos para Sergipe.

\section{Sergipe}

\section{População total, homens e mulheres 2000-2030}

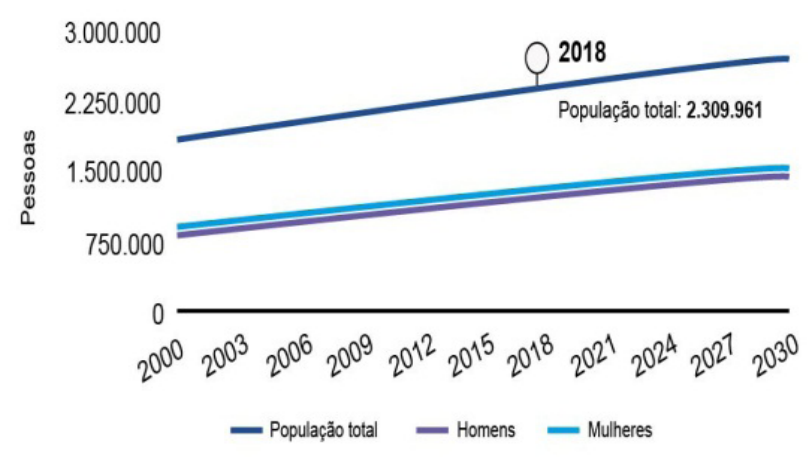

Fig 01: População Total de Sergipe 2.309.961 Fonte: IBGE, 2018.

Com base nestes dados é possível projetar o percentual de idosos, de acordo com o gráfico abaixo:

\section{Estimativa de população idosa em Sergipe 2018}

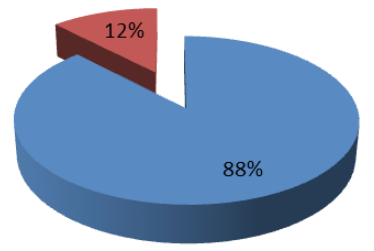

- população abaixo de 60 anos 2.029. 301 - população acima de 60 anos 280.660

Fig: 02.

Dados: Projeção da População do IBGE (2018), SIS 2016.

Da análise dos dados coletados em 20172018, foi possível observar o aumento do total de idosos residentes em ILPIs em relação ao ano de 2008, passando de 378 para 463 no estado de Sergipe. No entanto, esse aumento não representou uma ampliação percentual do número de idosos atendidos, muito pelo contrário, houve diminuição do 
percentual de idosos residentes em ILPIs, 2008) para um percentual projetado de 0,16\% de 0,3\% da população idosa em 2008 (IPEA, em 2018, como se verifica no gráfico abaixo:

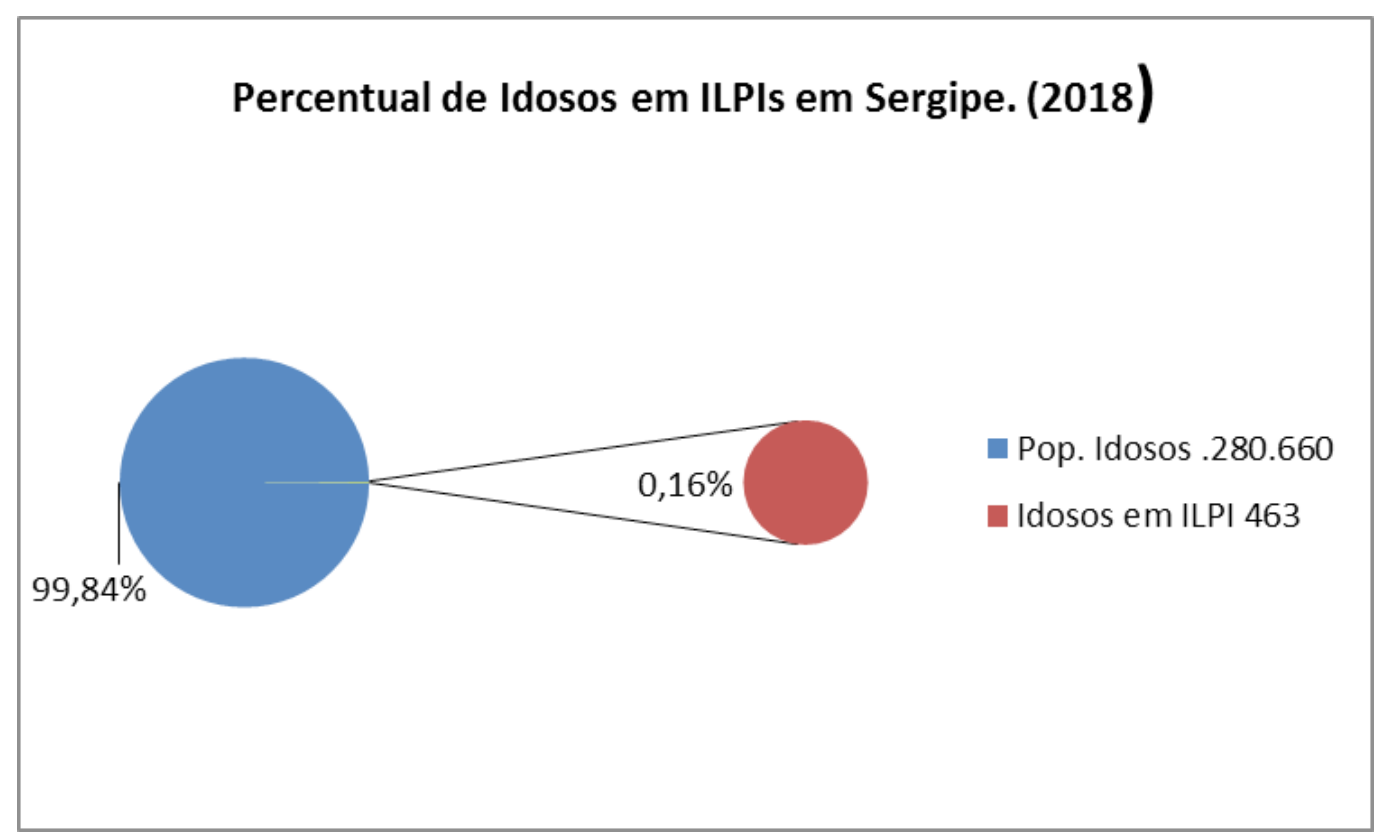

Figura: 03

Dados: Projeção da População IBGE (2018), Percentual de idosos indicado na SIS (2016), Pesquisa com gestores das ILPIs de Sergipe.

Outro dado preocupante refere-se ao fato de os gestores terem afirmado a ausência de apoio financeiro por parte do Poder Público federal, estadual e municipal para a manutenção das ILPIs. O que representa uma piora do cenário observado em 2008. Em alguns casos, o apoio do Poder Público às instituições privadas se restringe à cessão de funcionários públicos para prestar serviços nestas instituições.

As visitas registraram também as dificuldades relacionadas à limitação legal de gastos oriundos da aposentadoria ou do benefício dos idosos. Segundo eles, nos casos em que as despesas com o idoso exigem medicamentos específicos, ou de qualquer outro custo adicional, o gestor passa a enfrentar o desafio de cumprir a previsão legal do $\S 2^{\circ}$ do artigo 35 do Estatuto do Idoso, que estabelece o seguinte: "O Conselho Municipal do Idoso ou o Conselho Municipal da Assistência Social estabelecerá a forma de participação prevista no § 1, que não poderá exceder a 70\% (setenta por cento) de qualquer benefício previdenciário ou de assistência social percebido pelo idoso" (Brasil, 2003). O parágrafo primeiro e o caput exigem a formalização de contrato de prestação de serviços entre a entidade e o idoso, nesses termos.

A pesquisa buscou identificar a existência de idosos residentes em ILPIs que estivessem sendo beneficiados com a prestaçãojudicial de alimentos, sendo que não se identificou 
a existência de idoso nessa condição. Verificou-se ainda, com o apoio do Ministério Público Estadual, que a maioria das ILPIs tem conseguido comprovar os requisitos legais para a concessão do Benefício da Prestação Continuada (BPC) para idosos sem fonte de renda, nos termos do artigo 34, caput da Lei de Organização da Assistência Social- LOAS.
Ao que parece e confrontando a data da criação das ILPIs sergipanas ao marco legislativo da Política Nacional do Idoso, há a necessidade de modificação de um olhar de caridade para um olhar de garantia de direitos nestas instituições, ainda funcionando sob a lógica da filantropia e não como parte de uma política pública.

\section{ILPIs criadas antes e depois da criação da Política Nacional do Idoso em 1993}

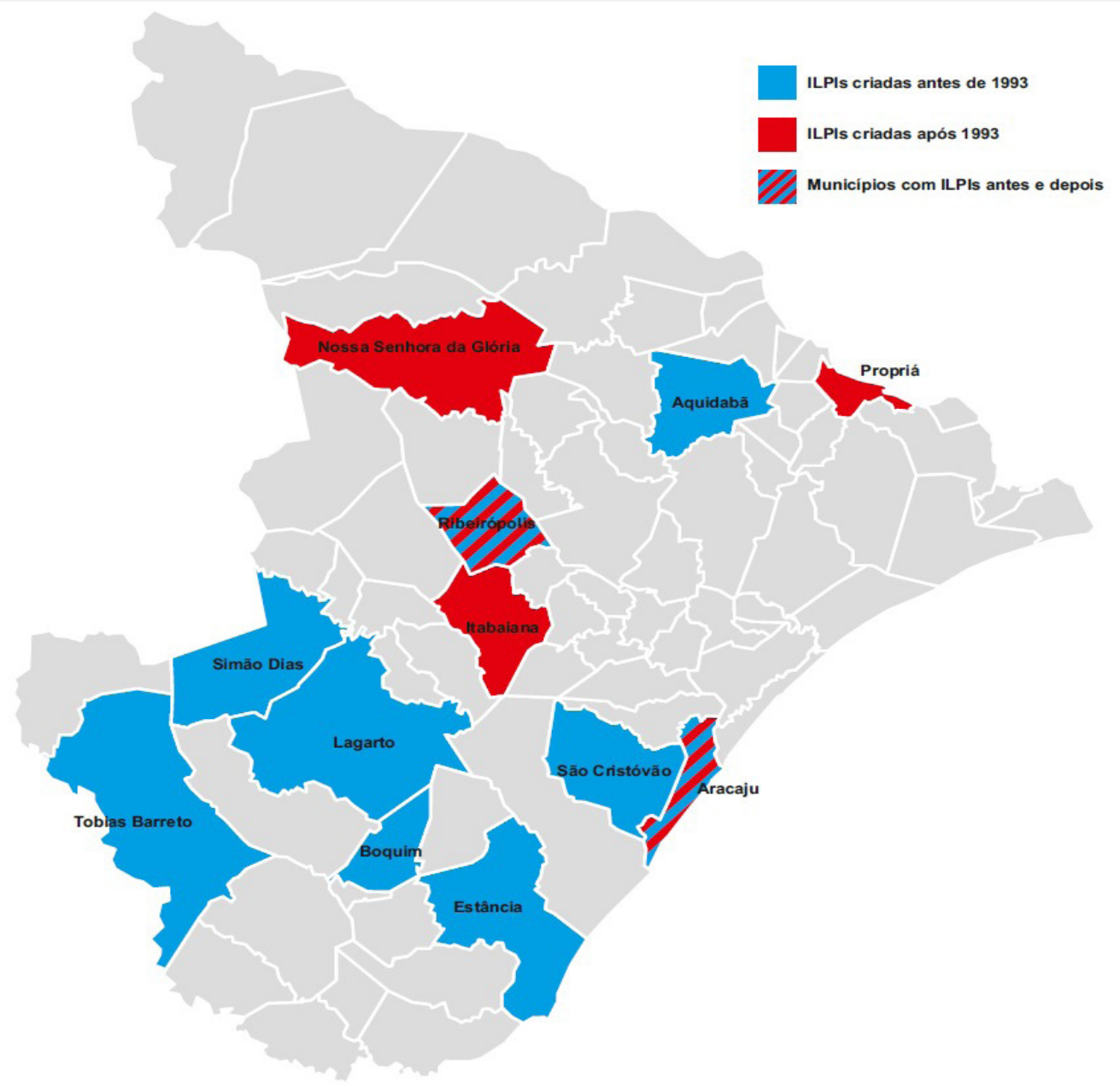

Figura 04.

Dados: Questionário aos Gestores

Embora seja necessário compreender o contexto de criação destas instituições, é preciso fortalecer uma mudança de olhar sobre o idoso nas ILPIs, seguindo a linha sugerida por Silva (2012): "assim, os direitos devem ser impregnados do respeito à dife- rença que reforça a lógica da dignidade humana, e não sacralizada com a aura da caridade e do assistencialismo que diminui a dimensão da cidadania" (Silva, 2012, p. 198).

Além disso, as políticas relacionadas à criação e manutenção de ILPIs em Sergipe não 
têm acompanhado o crescimento populacional de idosos. Apenas 02 instituições no Estado são mantidas pelo Poder Público. Uma delas localizada no município de Simão Dias, - Lar São Francisco de Assis, e a outra no município de Aracaju, a Casa Lar Nalde Barbosa.

O registro de um cenário legislativo que apontou o acolhimento em ILPIs e a modalidade asilar como última opção de cuidado, estabelecendo a vulnerabilidade social e ausência do apoio familiar como principal critério de acolhimento ao idoso, associado à ausência de ações do Poder Executivo que vem transferindo, na prática, a responsabilidade de cuidados asilares às instituições filantrópicas, denuncia uma forte ameaça à preservação da autonomia e das garantias do direito do idoso nas ILPIs de Sergipe.
O idoso nas ILPIs em Sergipe ilustra bem uma condição de vulnerabilidades variadas, como já mencionado. A vulnerabilidade individual, familiar e sociojurídica são facilmente comprovadas pelos dados obtidos, às quais se acrescem os riscos de perda de autonomia propostos por Foucault e Goffman para as instituições asilares.

A representação a seguir não pretende afastar outras possibilidades de quadros de análise, mas funciona como instrumento didático que aponta a necessidade de serem considerados vários aspectos, quando se pretende lançar um olhar sobre a garantia de direitos dos idosos como grupo vulnerável, e nos traz a reflexão de como uma vulnerabilidade pode ser sobreposta a outra se não ampliarmos o olhar.

\section{Interseção de Vulnerabilidades}

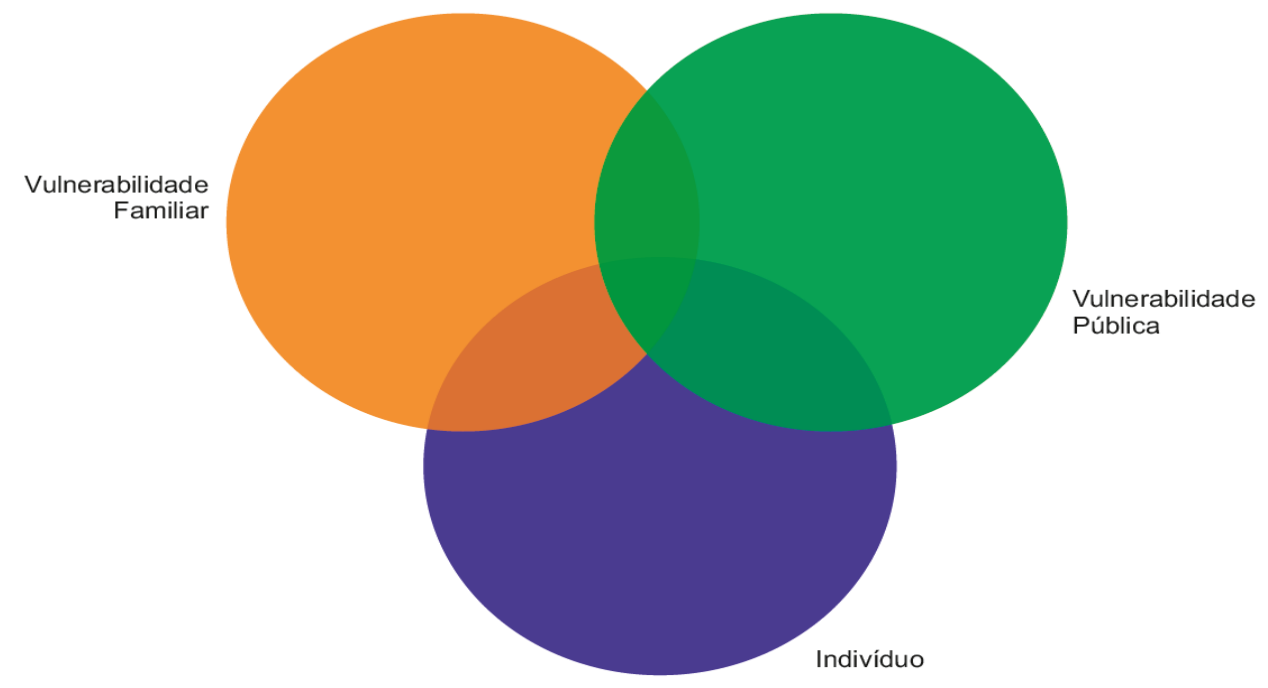
instituições do Estado e identificou elemen-

\section{CONSIDERAÇÕES FINAIS}

A pesquisa sobre as ILPIs de Sergipe levantou as características de filantropia e tos normativos que, na tentativa de proteger, acabaram por contribuir com a perda de autonomia do idoso na sociedade e, em especial, nas ILPIs. 
A luta pela preservação da autonomia dos idosos enfrenta as limitações naturais da senescência, da senilidade, e das próprias características sociais inerentes às ILPIs que podem representar uma quebra do convívio com outros grupos sociais externos à instituição.

De outra parte, o Direito do Idoso tem considerado a questão patrimonial em primeiro plano, deixando de observar outros aspectos importantes, como a autonomia do idoso e seu direito de escolha. em que pese a legislação, em especial o Estatuto do idoso, apontar a residência em ILPI como última opção a ser adotada, sua utilização ainda é significativa mesmo em face à precariedade de muitas das instituições que nasceram e permanecem sobrevivendo através da contribuição do idoso (aposentadoria ou BPC na maioria das vezes) e de doações que potencializam o caráter filantrópico das instituições.

Ao comparar os dados do IPEA de $2008 \mathrm{com}$ os dados da pesquisa de campo realizada em 2018, foi possível mapear o aumento do número de idosos residentes em ILPIs, embora não tenha acompanhado o crescimento da população idosa em geral. Os números representam um alerta para uma população que tende a precisar ainda mais desses serviços nos próximos anos.

O aumento da população de idosos no Brasil e em Sergipe, associado a uma ausência do Poder Executivo na criação e manutenção das ILPIs e da transferência de responsabilidade dos cuidados para a família e para instituições filantrópicas, criam um cenário de grande vulnerabilidade, que exige superar o olhar de caridade, para reconhecer o tema na perspectiva de garantia de direitos fundamentais As ILPIs precisam ser pensa- das como uma alternativa de escolha para qualquer idoso, inclusive com ampliação da oferta destes serviços pelo Poder Público.

É possível, de maneira geral, incluir o idoso das ILPIs de Sergipe, em um campo que reúne uma série de interseções de vulnerabilidades, que precisam ser enfrentadas ponto a ponto, evitando-se que um fator invisibilize o outro. Os residentes em ILPIs representam um grupo ainda mais vulnerável dentre a população de idosos, não somente por ocupar a última opção de modalidade de atendimento definida pela lei, mas também pela invisibilidade de sua condição. Ampliar o debate e o conhecimento acerca desta realidade foi o objetivo da pesquisa.

\section{REFERÊNCIAS}

Agência Nacional de Vigilância Sanitária. Resolução RDC n²83, de 26 de setembro de 2005.

Almeida, L. K. (2017). Abandono afetivo Inverso e sua responsabilidade civil e criminal. Revista Jus Navigandi, 22(5088).

Alcântara, A. O. (2004). Velhos Institucionalizados e Família: entre abafos e desabafos. Campinas: Editora Alínea.

Aristóteles, (2002). A política (R. L. Ferreira, trad.). São Paulo: Martins Fontes.

Beauvoir, S. (1970). A velhice. Rio de Janeiro: Nova Fronteira.

Braga, P. M. V. B. (2011). Curso de Direito do Idoso. São Paulo: Atlas.

Brasil. (1988). Constituição da República Federativa do Brasil.

Brasil. (1996). Decreto Federal 1.948 de 03 de julho de 1996, regulamenta a Política Nacional do Idoso estabelecida pela lei 8.842 de 1994, alterada pelo decreto 6.800 de 2009.

Brasil. (1994). Lei 8.842 de 1994. Política Nacional do Idoso.

Brasil. (2003). Lei 10.741 de 2003. Estatuto do Idoso.

Brasil. (2017) Ministério da Fazenda. Pessoa idosa e Previdência Social: demografia, mercado de trabalho e proteção social. Brasília: Secretaria de Previdência. 
Cabrera, C. C. (2006) Direitos da criança, do adolescente e do idoso: Doutrina e Legislação. Belo Horizonte: Del Rey.

Camarano, A., \& Kanso, S. (2007). As instituições de Longa Permanência para idosos no Brasil. Notas de pesquisa. Revista Brasileira de Estudos de População, 27 (1), 232-235.

Cicero, M. T. (2001). Saber Envelhecer e a Amizade (P. Neves, trad.). Porto Alegre: L\&PM.

Crenshaw, K. (2002). A Interseccionalidade na Discriminação de Raça e Gênero. Recuperado em 10 julho, 2018, de http://www.acaoeducativa.org.br/fdh/wp-content/uploads/2012/09/Kimberle-Crenshaw.pdf.

Debert, G. G. (1999) A Reinvenção da Velhice: Socialização e Processos de Reprivatização do Envelhecimento. São Paulo: Editora da Universidade de São Paulo, Fapesp.

Diniz, F. P. (2011). Direito dos Idosos na Perspectiva Civil Constitucional. Belo Horizonte: Arraes Editores.

Farfel, J. M. (2008). Fatores relacionados à senescência e à senilidade cerebral em indivíduos muito idosos: um estudo de correlação clínico patológicas. Tese de doutorado, Faculdade de Medicina da Universidade de São Paulo. São Paulo, SP, Brasil.

Foucault, M. (2007). Vigiar e Punir: nascimento da prisão (34a ed.). Petrópolis: Vozes.

Giacomo, M. A. (2017). A PEC 287/16 e a lesão a direitos fundamentais da pessoa com deficiência e ao idoso. Revista Jus Navigandi, 22(5049).

Goffman, E. (1992). Manicômios, Prisões e Conventos (4a ed.). São Paulo: Editora Perspectiva S.A.

Instituto Brasileiro de Geografia e Estatística. (2016). Ministério do Planejamento, Desenvolvimento e Gestão. Síntese de Indicadores Sociais: Uma análise das condições de vida da população brasileira. Rio de Janeiro.

Instituto Brasileiro de Geografia e Estatística. (2018). Projeção da População.

Instituto de Pesquisa Econômica Aplicada. (2008). Características das instituições de longa permanência para idosos - região Nordeste. Coordenação geral A. A. Camarano, Brasília.

LOPES, G. S. (2011). Envelhecimento e interdisciplinaridade: uma prática em construção. In: TRENCH, Belkis; ROSA, Tereza Etsuko da Costa. Nós e o outro: envelhecimento, reflexões, práticas e pesquisa/ organizado por São Paulo: Instituto de Saúde.

Morais, D. F. (2018). Um Olhar Sobre os Direitos Fundamentais e as Instituições de Longa Permanência para Idosos (ILPI) em Sergipe. Trabalho de Conclusão de Curso, Universidade Federal de Sergipe, SE, Brasil. SBGG. (2003). Sociedade Brasileira de Geriatria e Gerontologia. Manual de funcionamento para Instituição de Longa Permanência para Idosos. São Paulo. Silva, A. H. (2009). Idosos de ILPIs: Análise da Capacidade Funcional e Aptidão Funcional. Dissertação de mestrado, Universidade do Estado de Santa Catarina, Florianópolis, SC, Brasil.

Silva, N. T. R. (2012). Direito do Idoso: Tutela Jurídica Constitucional. Curitiba: Juruá.

Yeung, L. (2017). Jurimetria ou Análise Quantitativa de Decisões Judiciais. In. M. R. Machado (Org.). Pesquisar empiricamente o Direito (pp. 248-274). São Paulo: Rede de Estudos Empíricos em Direito.

Data de submissão: 28/08/2018

Data de aceite: 16/12/2019 